Review

\title{
Current Therapeutic Strategies and Prospects for EGFR Mutation-Positive Lung Cancer Based on the Mechanisms Underlying Drug Resistance
}

\author{
Yukari Tsubata *(D), Ryosuke Tanino $(\mathbb{D}$ and Takeshi Isobe
}

Division of Medical Oncology \& Respiratory Medicine, Department of Internal Medicine, Shimane University Faculty of Medicine, 89-1 Enya-Cho, Izumo 693-8501, Japan; rtanino@med.shimane-u.ac.jp (R.T.); isobeti@med.shimane-u.ac.jp (T.I.)

* Correspondence: ytsubata@med.shimane-u.ac.jp; Tel.: +81-853-20-2580

Citation: Tsubata, Y.; Tanino, R.; Isobe, T. Current Therapeutic Strategies and Prospects for EGFR Mutation-Positive Lung Cancer Based on the Mechanisms Underlying Drug Resistance. Cells 2021, 10, 3192. https://doi.org/10.3390/ cells10113192

Academic Editor: Steven G. Gray

Received: 17 September 2021

Accepted: 15 November 2021

Published: 16 November 2021

Publisher's Note: MDPI stays neutral with regard to jurisdictional claims in published maps and institutional affiliations.

Copyright: (C) 2021 by the authors Licensee MDPI, Basel, Switzerland. This article is an open access article distributed under the terms and conditions of the Creative Commons Attribution (CC BY) license (https:/ / creativecommons.org/licenses/by/ $4.0 /)$.
Abstract: The discovery of activating mutations in the epidermal growth factor receptor (EGFR) gene and the development of EGFR tyrosine kinase inhibitors (TKIs) have led to a paradigm shift in the treatment of non-small cell lung cancer (NSCLC). EGFR mutation-positive NSCLC is common in East Asia, and approximately 50\% of adenocarcinomas harbor EGFR mutations. Undoubtedly, EGFR-TKIs, with their promising efficacy, are the mainstay of primary therapy. However, even if tumor shrinkage is achieved, most patients become resistant to EGFR-TKIs and relapse; hence, EGFR-TKIs do not achieve a radical cure. The problem of the development of resistance to targeted drugs has been a persistent challenge. After the role of EGFR T790M mutation in acquired drug resistance was reported, osimertinib, a third-generation irreversible EGFR-TKI, was designed to overcome the resistance conferred by T790M mutation. In addition, some studies have reported the mechanism of drug resistance caused by mutations other than the T790M mutation and strategies to overcome them. Elucidating the mechanism underlying drug resistance development and combining therapeutic approaches are expected to further improve NSCLC prognosis.

Keywords: epidermal growth factor receptor gene mutation; epidermal growth factor receptor-tyrosine kinase inhibitor; acquired resistance; pemetrexed; targeted therapy

\section{Introduction}

The role of activating mutations in the epidermal growth factor receptor (EGFR) gene in non-small cell lung cancer (NSCLC) was reported in 2004 [1]. The development of EGFR tyrosine kinase inhibitor (TKI), as the therapeutic agent, radically overturned the conventional chemotherapy regimen for lung cancer, which was treated with cytotoxic anticancer agents until then [2,3]. Thus, the conventional method of synthesizing numerous candidate compounds and selecting an effective anticancer drug from among them has been replaced by a method of finding a target molecule first and then designing and developing anticancer drugs that specifically inhibit the target molecule. Since then, several molecular targeted drugs have been developed and clinically applied in patients harboring $A L K$ fusion genes, ROS1 fusion genes, BRAF mutations, NTRK fusion genes, and MET mutations [4-8]. Thus, personalized treatment based on the type of genetic mutations harbored by the patients is the new mainstay of chemotherapy for NSCLC.

Genes whose mutations and alterations are directly responsible for the increased growth and progression of cancer are collectively referred to as driver genes. Kinase inhibitors targeting these mutations/alternations are the primary therapeutic choices for patients harboring driver gene mutations. However, the development of drug resistance is one of the most common challenges associated with the use of kinase inhibitors. Patients treated with kinase inhibitors following fulfilling eligibility criteria show remarkable tumor shrinkage; however, despite the high efficacy of these kinase inhibitors, radical cure of stage 
IV NSCLC remains an unachieved goal because invariably, almost all patients develop acquired resistance within one to several years. Elucidating drug resistance mechanisms and developing new drugs to overcome resistance is indispensable for achieving higher efficacy and radical cancer cure. Osimertinib was the first drug developed to overcome resistance to kinase inhibitors. A third-generation irreversible EGFR-TKI, osimertinib overcomes the drug resistance acquired due to EGFR T790M mutation [9]. Since then, constant efforts have been made to develop drugs for overcoming resistance to kinase inhibitors and cytotoxic anticancer agents. New molecular targeted drugs and their combination with cytotoxic anticancer agents are expected to improve the prognosis of NSCLC patients further. This review focuses specifically on the latest treatments for EGFR mutation-positive lung cancer and the strategies aimed at overcoming drug resistance; moreover, we discuss the prospects for their use in clinical settings.

\section{Advances in the Treatment of EGFR Mutation-Positive Lung Cancer \\ 2.1. First and Second-Generation EGFR-TKI Monotherapy}

EGFR mutations are found in approximately $15 \%$ of lung adenocarcinomas cases in Europe and the United States, and 55\% cases in East Asia [10]. The exon 19 deletion mutation and L858R mutation account for more than $90 \%$ of EGFR mutations, making tumors highly sensitive to EGFR-TKIs [11]. Other mutations are rather uncommon, and a few among them, such as G719X, L861Q, and S768I, turn tumors highly sensitive to EGFR-TKIs; in NSCLC patients harboring these mutations, EGFR-TKIs are considered as the main therapeutic agents. On the contrary, patients harboring exon 20 insertion mutations or T790M mutations as primary mutations are resistant to EGFR-TKI and are not indicated for treatment [12].

Phase III clinical trials comparing the use of EGFR-TKIs (gefitinib and erlotinib) with platinum in NSCLC harboring a deletion mutation in exon 19 and the L858R mutation in exon $21[2,3,13,14]$ showed that EGFR-TKI monotherapy significantly improved the response rate and progression-free survival (PFS) compared to platinum combination therapy, establishing it as the standard of care (Table 1). Compared to EGFR-TKIs, phase-III clinical trials comparing afatinib (LUX-Lung7) and dacomitinib (ARCHER1050) (both second-generation EGFR-TKIs) with gefitinib (a first-generation EGFR-TKI) $[15,16]$ reported that PFS (the primary endpoint) was 13.0 months vs. 10.4 months (HR 0.81, 95\% C.I. 0.62-1.05) for LUX-Lung7 and 14.7 months vs. 9.2 months (HR 0.59, 95\% C.I. 0.47-0.74) for ARCHER1050; in both the cases, the secondgeneration EGFR-TKI group showed superior outcomes (Table 1). Based on the results of these pivotal clinical trials, both first- and second-generation EGFR-TKIs are being used in clinical settings worldwide.

\subsection{Treatment of EGFR T790M Acquired Resistance}

Osimertinib is an irreversible EGFR inhibitor designed to inhibit both EGFR-sensitive and T790M-resistant mutations and is classified as a third-generation EGFR-TKI. In the AURA3 study, a phase III trial comparing osimertinib with platinum-based combination therapy in patients who tested positive for the T790M resistance mutation after treatment with first- and second-generation EGFR-TKIs [9], the median PFS (the primary endpoint) significantly prolonged to 10.1 months vs. 4.4 months (HR $0.30,95 \%$ CI $0.23-0.41$ ). The frequency of grade 3 or higher toxicity was lower with osimertinib. Therefore, if a therapeutic agent other than osimertinib is chosen for the first-line therapy, the EGFR mutation status should be rechecked after disease progression, and if the T790M mutation is detected, osimertinib use should be strongly considered. 
Table 1. List of clinical trials evaluating EGFR-TKI monotherapy in EGFR-mutated lung cancer.

\begin{tabular}{|c|c|c|c|c|c|c|c|c|c|}
\hline \multirow{3}{*}{$\begin{array}{c}\text { Trial } \\
\text { (Reference) }\end{array}$} & \multirow{3}{*}{$\begin{array}{c}\text { Target EGFR } \\
\text { Mutation }\end{array}$} & \multirow{3}{*}{$\begin{array}{l}\text { Experimental } \\
\text { Therapy }\end{array}$} & \multirow{3}{*}{$\begin{array}{l}\text { Control } \\
\text { Therapy }\end{array}$} & \multicolumn{3}{|c|}{ PFS $^{1}$ (Primary Outcome) } & \multicolumn{3}{|c|}{ Overall Survival } \\
\hline & & & & \multicolumn{2}{|c|}{ Months } & \multirow{2}{*}{$\begin{array}{c}\text { HR }^{4} \\
\left(95 \% \text { C.I. }{ }^{5}\right)\end{array}$} & \multicolumn{2}{|c|}{ Months } & \multirow{2}{*}{$\begin{array}{c}\text { HR } \\
\text { (95\% C.I.) }\end{array}$} \\
\hline & & & & $\operatorname{Exp}^{2}$ & $\mathrm{Ctrl}^{3}$ & & $\operatorname{Exp}$ & Ctrl & \\
\hline \multirow{2}{*}{ NEJ002(2) } & \multirow{2}{*}{$\begin{array}{l}\text { Sensitizing } \\
\text { mutation }\end{array}$} & \multirow{2}{*}{ Gefitinib } & \multirow{2}{*}{$\mathrm{Cb}^{6} / \mathrm{PTX}$} & \multirow{2}{*}{10.8} & \multirow{2}{*}{5.4} & 0.33 & \multirow{2}{*}{30.5} & \multirow{2}{*}{23.6} & \multirow[b]{2}{*}{. } \\
\hline & & & & & & $(0.22-0.41)$ & & & \\
\hline \multirow{2}{*}{ WJTOG 3405(3) } & \multirow{2}{*}{$\begin{array}{c}\text { Ex19_del } \\
\text { Ex21_L858R }\end{array}$} & \multirow{2}{*}{ Gefitinib } & \multirow{2}{*}{$\begin{array}{l}\text { CDDP } \\
7 / \text { DTX }^{8}\end{array}$} & \multirow{2}{*}{9.2} & \multirow{2}{*}{6.3} & 0.489 & \multirow{2}{*}{30.9} & \multirow{2}{*}{$\mathrm{NR}^{9}$} & 1.638 \\
\hline & & & & & & $(0.336-0.710)$ & & & $(0.749-3.582)$ \\
\hline EURTAC(13) & $\begin{array}{c}\text { Ex19_del } \\
\text { Ex21_L858R }\end{array}$ & Erlotinib & CDDP & 9.7 & 5.2 & & - & - & - \\
\hline \multirow{2}{*}{ EURTAC(13) } & \multirow{2}{*}{$\begin{array}{c}\text { Ex19_del } \\
\text { Ex21_L858R }\end{array}$} & \multirow{2}{*}{ Erlotinib } & $\mathrm{Cb} / \mathrm{DTX}$ & \multirow{2}{*}{9.7} & \multirow{2}{*}{5.2} & 0.37 & \multirow{2}{*}{-} & \multirow{2}{*}{-} & \multirow{2}{*}{ - } \\
\hline & & & GEM $^{10}$ & & & $(0.25-0.54)$ & & & \\
\hline OPTIMAL (14) & $\begin{array}{c}\text { Ex19_del } \\
\text { Ex21_L858R }\end{array}$ & Erlotinib & $\mathrm{Cb} / \mathrm{GEM}$ & 13.1 & 4.6 & 0.16 & - & - & - \\
\hline OPTIMAL (14) & $\begin{array}{c}\text { Ex19_del } \\
\text { Ex21_L858R }\end{array}$ & Erlotinib & $\mathrm{Cb} / \mathrm{GEM}$ & 13.1 & 4.6 & $(0.10-0.26)$ & - & - & - \\
\hline LUX-Lung 7 (15) & $\begin{array}{c}\text { Ex19_del } \\
\text { Ex21_L858R }\end{array}$ & Afatinib & Gefitinib & 11 & 10.9 & 0.74 & 27.9 & 24.5 & 0.86 \\
\hline LUX-Lung 7 (15) & $\begin{array}{c}\text { Ex19_del } \\
\text { Ex21_L858R }\end{array}$ & Afatinib & Gefitinib & 11 & 10.9 & $(0.57-0.95)$ & 27.9 & 24.5 & $(0.66-1.12)$ \\
\hline ARCHER 1050 (16) & $\begin{array}{c}\text { Ex19_del } \\
\text { Ex21_L858R }\end{array}$ & Dacomitinib & Gefitinib & 14.7 & 9.2 & 0.59 & 34.1 & 26.8 & 0.76 \\
\hline ARCHER 1050 (16) & $\begin{array}{c}\text { Ex19_del } \\
\text { Ex21_L858R }\end{array}$ & Dacomitinib & Gefitinib & 14.7 & 9.2 & $(0.47-0.74)$ & 34.1 & 26.8 & $(0.582-0.993)$ \\
\hline FLAURA (17) & $\begin{array}{c}\text { Ex19_del } \\
\text { Ex21_L858R }\end{array}$ & Osimertinib & Gefitinib & 18.9 & 10.2 & 0.46 & 38.6 & 31.8 & 0.799 \\
\hline FLAURA (17) & $\begin{array}{c}\text { Ex19_del } \\
\text { Ex21_L858R }\end{array}$ & Osimertinib & Erlotinib & 18.9 & 10.2 & $(0.37-0.57)$ & 38.6 & 31.8 & $(0.641-0.997)$ \\
\hline
\end{tabular}

${ }^{1}$ PFS, progression free survival; ${ }^{2}$ Exp, Experimental therapy; ${ }^{3} \mathrm{Ctrl}$, Control therapy; ${ }^{4}$ HR, hazard ratio; ${ }^{5}$ C.I., confidence interval;

${ }^{6} \mathrm{Cb}$, carboplatin; ${ }^{7} \mathrm{CDDP}$, cisplatin; ${ }^{8} \mathrm{DTX}$, docetaxel; ${ }^{9} \mathrm{NR}$, not reached; ${ }^{10} \mathrm{GEM}$, gemcitabine.

\subsection{Third-Generation EGFR-TKI Monotherapy}

The FLAURA study, a phase-III trial comparing single-agent osimertinib with firstgeneration EGFR-TKIs (gefitinib or erlotinib) in patients with EGFR mutations (exon 19 deletion mutation and exon 21 L858R mutation) [17], reported that PFS (the primary endpoint) significantly prolonged with osimertinib treatment, 18.9 months vs. 10.2 months (HR 0.46, 95\% C.I. 0.37-0.57). Overall survival (OS) also significantly improved with osimertinib, 38.6 months vs. 31.8 months (HR 0.799, 95\% C.I. 0.641-0.997). In terms of toxicity such as skin rash and liver damage, osimertinib tends to be milder than firstgeneration EGFR-TKIs, and osimertinib monotherapy has been established as one of the standard therapies for the first-line treatment of EGFR mutation-positive NSCLC (Table 1).

Meanwhile, several clinical trials have begun exploring the usefulness of osimertinib combination therapy. Combination therapy of osimertinib and CBDCA/PEM in FLAURA2, an international safety run study, exhibited a manageable safety and tolerability profile in first-line settings [18]. In addition, in phase II clinical trial (WJOG9717L) examining the efficacy of bevacizumab (an angiogenesis inhibitor) and osimertinib, the primary endpoint, PFS, did not show a statistically significant prolongation of survival [19]. Further assessment is expected.

\subsection{EGFR-TKI Combination Therapy}

Combination therapies using EGFR-TKIs, and cytotoxic agents or angiogenesis inhibitors are also being explored (Table 2). Two phase-III trials compared the patient outcomes following treatment with gefitinib alone with that in response to gefitinib plus carboplatin plus pemetrexed (PEM) in combination with cytotoxic agents. The NEJ009 trial [20] 
showed improved PFS (the primary endpoint) in the combination group (20.9 months vs. 11.9 months, HR $0.490,95 \%$ C.I. 0.39-0.62). The median OS in the combination group was an astounding 50.9 months, indicating that patients with EGFR mutation-positive lung cancer may now have 5-year survival even after being diagnosed with unresectable lung cancer. A study conducted by Noronha et al. also showed prolongation of the primary endpoints, PFS, and OS [21].

Table 2. List of clinical trials evaluating EGFR-TKI combination therapy in EGFR-mutated lung cancer.

\begin{tabular}{|c|c|c|c|c|c|c|c|c|c|}
\hline \multirow{3}{*}{$\begin{array}{c}\text { Trial } \\
\text { (Reference) }\end{array}$} & \multirow{3}{*}{$\begin{array}{l}\text { Target EGFR } \\
\text { Mutation }\end{array}$} & \multirow{3}{*}{$\begin{array}{l}\text { Experimental } \\
\text { Therapy }\end{array}$} & \multirow{3}{*}{$\begin{array}{l}\text { Control } \\
\text { Therapy }\end{array}$} & \multicolumn{3}{|c|}{ PFS $^{1}$ (Primary Outcome $^{\dagger}$ ) } & \multicolumn{3}{|c|}{ Overall Survival } \\
\hline & & & & \multicolumn{2}{|c|}{ Months } & \multirow{2}{*}{$\begin{array}{c}\text { HR }^{4} \\
\left(95 \% \text { C.I. }^{5}\right)\end{array}$} & \multicolumn{2}{|c|}{ Months } & \multirow{2}{*}{$\begin{array}{c}\text { HR } \\
\text { (95\% C.I.) }\end{array}$} \\
\hline & & & & $\operatorname{Exp}^{2}$ & $\mathrm{Ctrl}^{3}$ & & Exp & Ctrl & \\
\hline \multirow{2}{*}{$\begin{array}{l}\text { NEJ009 } \\
(20)\end{array}$} & \multirow{2}{*}{$\begin{array}{l}\text { Sensitizing } \\
\text { mutation }\end{array}$} & \multirow{2}{*}{$\begin{array}{c}\mathrm{Cb}^{6} / \mathrm{PEM}^{7} / \\
\text { Gefitinib }\end{array}$} & \multirow{2}{*}{ Gefitinib } & \multirow{2}{*}{20.9} & \multirow{2}{*}{11.9} & 0.49 & \multirow{2}{*}{50.9} & \multirow{2}{*}{28.8} & 0.72 \\
\hline & & & & & & $(0.39-0.62)$ & & & $(0.55-0.95)$ \\
\hline \multirow{2}{*}{$\begin{array}{l}\text { Noronha } \\
\text { trial }(21)\end{array}$} & \multirow{2}{*}{$\begin{array}{l}\text { Sensitizing } \\
\text { mutation }\end{array}$} & \multirow{2}{*}{$\begin{array}{l}\mathrm{Cb} / \mathrm{PEM} / \\
\text { Gefitinib }\end{array}$} & \multirow[b]{2}{*}{ Gefitinib } & \multirow{2}{*}{16.0} & \multirow{2}{*}{8.0} & 0.51 & \multirow{2}{*}{$\mathrm{NR}^{8}$} & \multirow{2}{*}{17} & 0.45 \\
\hline & & & & & & $(0.39-0.66)$ & & & $(0.31-0.65)$ \\
\hline \multirow{2}{*}{$\begin{array}{l}\text { NEJ026 } \\
(22,23)\end{array}$} & \multirow{2}{*}{$\begin{array}{c}\text { Ex19_del } \\
\text { Ex21_L858R }\end{array}$} & \multirow{2}{*}{$\begin{array}{c}\text { Erlotinib/ } \\
\text { Bevacizumab }\end{array}$} & \multirow{2}{*}{ Erlotinib } & \multirow[b]{2}{*}{16.9} & \multirow{2}{*}{13.3} & 0.605 & \multirow{2}{*}{50.7} & \multirow{2}{*}{46.2} & 1.007 \\
\hline & & & & & & $(0.417-0.877)$ & & & $(0.681-1.49)$ \\
\hline \multirow{2}{*}{$\begin{array}{l}\text { RELAY } \\
\text { (24) }\end{array}$} & \multirow{2}{*}{$\begin{array}{c}\text { Ex19_del } \\
\text { Ex21_L858R }\end{array}$} & \multirow{2}{*}{$\begin{array}{c}\text { Erlotinib/ } \\
\text { Bevacizumab }\end{array}$} & \multirow{2}{*}{ Erlotinib } & \multirow{2}{*}{19.4} & & 0.59 & & & 0.83 \\
\hline & & & & & 12.4 & $(0.46-0.76)$ & NR & NR & $(0.53-1.30)$ \\
\hline
\end{tabular}

Outcomes of combination therapy with erlotinib and anti-angiogenesis agents have also been evaluated in several trials. The NEJ026 trial $[22,23]$ was a phase III trial that compared erlotinib monotherapy with erlotinib plus bevacizumab; PFS, the primary endpoint, was prolonged in the combination therapy group (16.9 months vs. 13.3 months, HR $0.605,95 \%$ C.I. 0.417-0.877), but OS did not improve. The RELAY trial [24] was a phase III trial comparing erlotinib alone with erlotinib plus ramucirumab and the PFS (primary endpoint) prolonged in the combination group (19.4 months vs. 12.4 months, HR 0.59, 95\% C.I. 0.46-0.79).

It remains inconclusive whether starting the first-line treatment of EGFR mutationpositive lung cancer with osimertinib alone, with other EGFR-TKIs alone, or using combination treatment first and then using osimertinib after T790M is detected, improves the prognosis. A study to confirm the efficacy of osimertinib plus a cytotoxic anticancer agent (NCT04035486) and a clinical trial comparing osimertinib with erlotinib plus ramucirumab in L858R mutation-positive patients only (JapicCTI-184146) are ongoing, and their results are awaited.

\subsection{Immunotherapy for EGFR-Mutated Lung Cancer}

These days, immune checkpoint inhibitors (ICIs) (including anti-PD-1/L1 and antiCTLA-4 antibodies) are an essential therapeutic option in the treatment of lung cancer. EGFR activation may increase PD-L1 expression in tumor cells by upregulating PI3K and activating the IL-6/JAK/STAT3 pathway and MEK/ERK pathway [25-28]. It has also been reported that the administration of EGFR-TKIs has a positive effect on the tumor microenvironment [29-31], but the specific molecules involved in PD-L1 activation have not yet been elucidated. Furthermore, the correlation between the presence of EGFR mutations and PD-L1 expression is still controversial. However, the intensity and treatment susceptibility of PD-L1 expression in T790M-negative patients are consistently correlated, regardless of prior treatment with EGFR-TKIs [32,33]. This indicates that elucidating the relationship between PD-L1 expression and EGFR-TKI susceptibility, as well as the resistance mechanisms, may provide new avenues for overcoming EGFR-TKI resistance. 
On the other hand, the therapeutic effect of combining ICIs and chemotherapy for treatment after EGFR-TKI failure remains unclear because EGFR-positive lung cancer has been excluded from many clinical trials [34]. The IMpower150 study group examined the effect of adding atezolizumab to CBDCA/PTX/BEV in chemotherapy-naive non-squamous NSCLC and allowed registration of EGFR-positive lung cancer after EGFR-TKI failure. A subgroup analysis of this cohort revealed useful results for median OS in the atezolizumabadded group (not evaluated vs. 17.5 months, HR 0.31) [35]. However, the therapeutic effect of ICIs alone for EGFR-positive lung cancer is limited, and the PFS of nivolumab monotherapy after EGFR-TKI failure is only 1.7 months [36]. It is presumed that such a gap between the results of preclinical studies and actual clinical trials is due to various factors, such as tumor heterogeneity, PD-L1 IHC scoring criteria, and treatment history. Because some EGFR mutation-positive patients may benefit from immunotherapy, it is important to elucidate the molecules primarily involved in the mechanism of PD-L1 activation and EGFR-TKI resistance and to investigate their association. Identifying predictors of therapeutic efficacy is considered to be an important element of personalized treatment.

\section{Mechanisms Underlying Acquired Resistance to EGFR-TKIs}

Broadly three mechanisms of acquired resistance to EGFR-TKIs have been reported [37]: (1) alteration of the target via EGFR-TKI susceptibility mutations (acquiring T790M mutation), (2) activation of alternative pathways due to genetic alterations such as MET amplification and KRAS mutation, and (3) alteration of the phenotype, such as transformation to small cell lung cancer or EMT (epithelial-mesenchymal transition). Furthermore, these pathways may be co-activated in a single case, and their crosstalk can further complicate the cancer course and patient outcomes.

\subsection{Mechanisms Underlying Development of Resistance to First- and Second-Generation EGFR-TKIs}

Since first-generation EGFR-TKIs were introduced in clinical practice, the molecular mechanisms involved in EGFR-TKI acquired resistance have been vigorously investigated $[37,38]$. The most frequent mechanism associated with acquired resistance involves the T790M secondary mutation. Under physiological conditions, EGFR, a receptor-type tyrosine kinase, forms a dimer when bound by its ligands such as EGF and TGF- $\alpha$ and transmits pro-proliferation signals in the cells via autophosphorylation and assuming an activated conformation. In EGFR mutation-positive lung cancers, exon 19 deletion mutation and exon 21 L858R point mutation, among others, cause the kinase to become homeostatically activated in a ligand-independent manner [39]. This leads to the transmission of excessive pro-survival and pro-proliferation signals, which in turn lead to cancer initiation and progression; the efficacy of EGFR-TKIs lies in lowering these excessive pro-survival and pro-proliferation signals. When the T790M mutation occurs in the ATP-binding pocket of the kinase, the affinity of the kinase for EGFR-TKI decreases compared to that for ATP, leading to the development of drug resistance [40]. Generally, tumor heterogeneity in which multiple clones with different genotypes are present in one tumor mass has been observed [41]. It is known that in EGFR mutation-positive lung cancer, T790M-positive cells are present at an incidence rate of $79.9 \%$, albeit at a low frequency when analyzed by an ultrasensitive method ( $0.009 \%$ to $26.9 \%)$, even before EGFR-TKI treatment [42]. It is hypothesized that these T790M-positive cells are protected from the effects of EGFR-TKI treatment and resistance acquired via the T790M mutation occurs frequently. Analysis using a highly sensitive method showed that the T790M mutation is present in $68 \%$ of cases of EGFR-TKI acquired resistance [43]. Osimertinib was developed based on the clear proof of concept that T790M was a potential target for therapeutic drug development and was successfully applied in clinical settings, even though it could not achieve a radical cure for NSCLC. Amplification of genes, such as MET and ERBB2, transformation to small cell lung cancer, hepatocyte growth factor (HGF) overexpression, EMT transition, and PIK3CA mutation/reduced PTEN expression are other events that can occur after treatment with first- and second-generation EGFR-TKIs and with cancer progression, leading to the 
development of drug resistance [44]. In addition, Akt is frequently activated in tumors after treatment with first- and second-generation EGFR-TKIs [45]. However, none of the drugs targeting these mechanisms have so far been applied in clinical settings.

\subsection{Mechanisms Underlying Development of Resistance to Third-Generation EGFR-TKIs}

The mechanisms underlying resistance to osimertinib, a third-generation EGFR-TKI, have been investigated [46,47], and the presence of the EGFR C797S mutation in addition to the T790M mutation (T790M/C797S double-positive) has been proposed as one of the main mechanisms responsible for resistance acquisition in T790M mutation-positive lung cancer [48]. C797S reduces the affinity between osimertinib and the EGFR kinase domain and increases the relative affinity for ATP. EGFR-TKIs that can inhibit the kinase activity of EGFR in T790M/C797S double-positive lung cancer have also been developed, but their clinical usefulness is yet to be approved. In the case of T790M loss, several genetic alterations have been observed, including those related to transformation to small cell lung cancer, $M E T$ amplification, ERBB2 amplification/mutation, PIK3CA mutation, KRAS mutations, and oncogenic gene fusion involving RET, FGFR3, and BRAF.

The frequency and spectrum of resistance mechanisms observed when osimertinib is used as first-line therapy in T790M-negative patients are different from those in T790Mpositive patients after second-line therapy [47]. The incidence of drug resistance acquisition has been increasing and becoming more complex in nature. In addition to the drug resistance conferred by the C797S mutation in EGFR, amplification of the MET gene as a bypass pathway, alteration in RAS-RAF-MAPK pathway, ROS1 fusion gene, PIK3CA mutation, and transformation to small cell lung cancer are other mechanisms that impart drug resistance. Thus, the resistance mechanisms acquired after osimertinib treatment are rather complex, and therefore, it is challenging to treat osimertinib resistance using a single therapeutic approach. Even if specific resistance factors are identified, there are currently no insurance-approved therapies to target these factors. At present, the most notable therapeutic strategy for addressing acquired resistance is the combination of amivantamab, a bispecific antibody targeting EGFR and MET, and lazertinib, a third-generation EGFRTKI. In phase I clinical trial conducted in EGFR mutation-positive patients with disease progression after osimertinib, the overall response rate for both drugs was $36 \%$ [49]. A subgroup analysis of MET-based resistant cases revealed good results, with a response rate of $75 \%$. Although HER3 alterations are not known to mediate resistance to EGFR-TKIs, HER3-targeted patritumab deruxtecan was used in phase I clinical trials in EGFR-TKI resistant cases and produced a response rate of 39\%, which is a good result, regardless of the background resistance mechanism [50]. With respect to treatment after failure of 3rd generation EGFR-TKIs, there is an ongoing debate as to whether to target a specific resistance-forming mechanism or to promote the development of drugs that are widely indicated regardless of the resistance-forming mechanism. The use of next-generation sequencing to confirm the details of these genetic mutations in daily practice remains uncommon for several reasons, affecting the pace of resistance factor identification. EGFR mutation-positive lung cancer is a classic example of monoclonal evolution in tumors. Even within an individual, the genomic landscape of individual tumors is heterogeneous, and the therapeutic agent of choice reveals the predominant subclones that are least susceptible to treatment over time [51]. Liquid biopsies have enabled the monitoring of genomic changes by analyzing circulating tumor (ct) DNA. Several clinical trials have reported that clearance of EGFR-activated mutations several weeks after the start of treatment is associated with good PFS, and liquid biopsy results have also become predictive markers for efficacy and residual lesions [52-55]. If the measurement of plasma ct DNA can be popularized in general practice, it would be possible to select treatments based on resistance status more widely (Figure 1). 


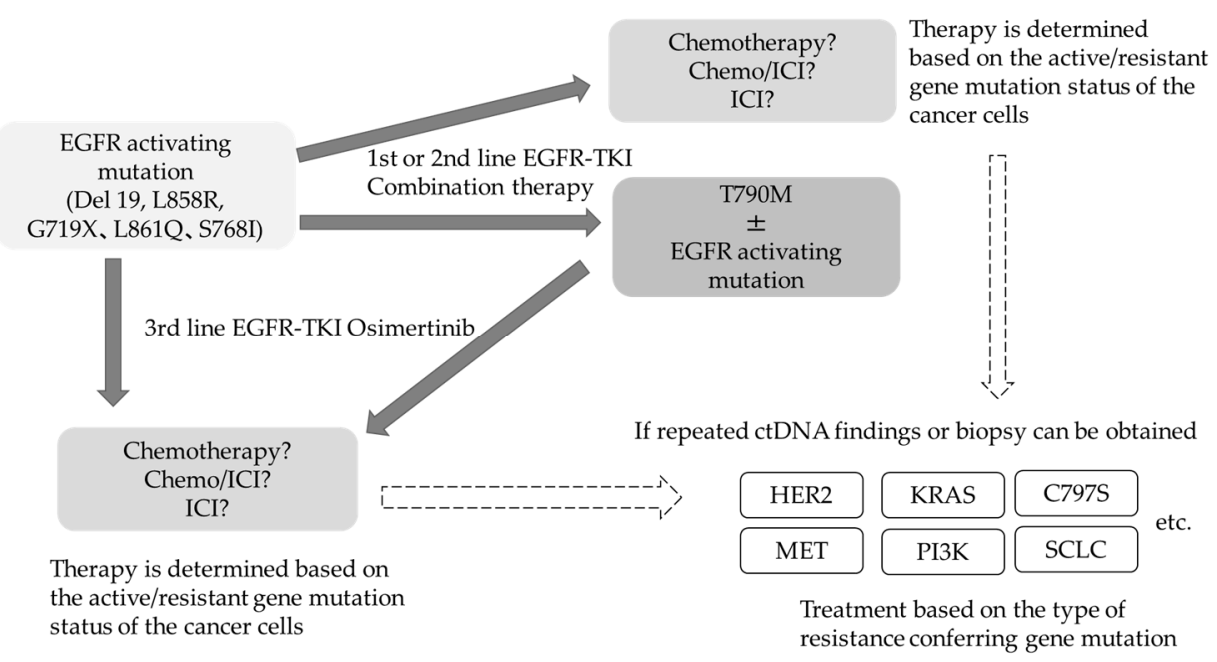

Figure 1. Future prospects of treatment algorithms for EGFR mutation-positive lung cancer.

\section{Possibility of Combination Therapy with EGFR-TKI and Other Drugs}

For curative treatment, one strategy for drastically reducing the number of remaining tumor cells and preventing the development of drug resistance is to combine EGFR-TKI with other therapeutic agents. Based on this concept, combination therapy, including EGFR-TKIs and cytotoxic anticancer agents or angiogenesis inhibitors, is being explored. The usefulness of combination therapy is positioned as a therapeutic strategy aimed at curative treatment in the sense that cancer cells can be killed regardless of the genetic background, taking into account that tumor heterogeneity comprises a population of cells with various genetic backgrounds. In fact, some combination regimens have been shown to prolong the duration of response compared to TKI monotherapy, but it is still controversial whether these strategies increase the cure rate.

\subsection{Combination Therapy with Cytotoxic Anticancer Agents}

Although EGFR-TKIs are the key drug for treating EGFR mutation-positive lung cancer, cytotoxic anticancer agents remain an important treatment option. Cytotoxic anticancer agents attack cancer cells with or without EGFR mutations, and their combination with EGFR-TKIs may prevent the growth of EGFR-TKI-resistant cells. A next-generation sequencing-based study revealed that very few T790M-positive cells exist among EGFR mutation-positive cells at the early stage of cancer before the treatment is started [56]. Thus, it is prudent to attack these cells with cytotoxic anticancer agents from the very beginning, since T790M acquired resistance is expected to occur in EGFR T790M mutation-positive cells, which were initially very few. Moreover, cells without T790M mutation may escape cell death by activating bypass pathways of survival and proliferation, other than those mediated by EGFR, upon exposure to EGFR-TKIs. Therefore, combination therapy with cytotoxic anticancer agents is expected to be more effective in such cases.

For combination anticancer therapeutic approaches, the use of carboplatin and PEM is recommended based on the results of clinical trials [20,21]. However, with the combined use of cytotoxic chemotherapy, treatment-related adverse events of Common Terminology Criteria for Adverse Events (CTCAE) grade 3 or higher increased to $65.3 \%$ (31.0\% for TKI monotherapy). In particular, grade 3 or higher neutropenia was as high as $31.2 \%$ with combination therapy, compared to $0.6 \%$ with TKI monotherapy [20]. The changes in frequency and spectrum of the resistance mechanism in response to combination therapy using PEM and EGFR-TKI remain undetermined and should be explored in future studies. In vitro, PEM has been reported to regulate the PI3K/Akt pathway downstream of EGFR $[57,58]$. We previously reported that PTK2/FAK activation may occur in cells that acquire drug resistance in response to PEM and EGFR-TKI treatment [59]. Thus, the cells treated with combination therapy may activate combination signaling pathways including 
those activated in response to targeted and non-targeted drugs, thereby leading to the emergence of a novel resistance mechanism. We are currently investigating such pathways using cells that have acquired resistance to the combination therapy. In the future, it will be necessary to evaluate whether the simultaneous or sequential use of two drugs is more likely to improve prognosis from the perspective of resistance mechanisms.

\subsection{Combination Therapy with Angiogenesis Inhibitors}

Scientific studies have shown that aspects of the tumor microenvironment, such as survival signals from fibroblasts around cancer cells and poor vascularization around cancer cells, may cause cancer cells to survive EGFR-TKI monotherapy [60]. In fact, combination therapy with angiogenesis inhibitors and EGFR-TKIs, which is believed to inhibit neovascularization, has been shown to prolong PFS in several clinical trials [22,23]. However, there is no clear evidence that it increases the cure rate; moreover, the RELAY study [24], which compared erlotinib monotherapy with erlotinib plus ramucirumab combination therapy, reported no difference in the detection rate of T790M during disease progression. With the combined use of angiogenesis inhibitors, hypertension of CTCAE grade 3 or higher increased to $23 \%$ (compared to $1 \%$ with TKI monotherapy) [24]. Whether the combination of angiogenesis inhibitors and EGFR-TKIs modifies the resistance mechanism is a subject for further investigation. The mechanisms of resistance to angiogenesis inhibitors also need to be studied in more detail [61,62]. Furthermore, a phase II trial comparing single-agent osimertinib with the combination of osimertinib plus bevacizumab in patients with the T790M mutation [63] showed no benefit in prolonging PFS in the combination group. Therefore, it may be necessary to identify a biomarker to stratify patients who can benefit from the combination therapy using angiogenesis inhibitors.

\section{Conclusions}

EGFR-TKIs remain the mainstay of pharmacotherapy for the treatment of EGFR mutation-positive lung cancer. However, recurrence due to cancer heterogeneity and mechanisms underlying drug resistance remain persistent challenges. Moreover, it is challenging to achieve a radical cure using a single agent. On the contrary, remarkable progress has been made in elucidating the mechanisms underlying the development of resistance to molecularly targeted drugs, and it will not be long before therapeutic strategies based on the results of scientific studies will be available in clinical practice. To determine the optimal approach, we need to design a therapeutic strategy to overcome the resistance mechanism in cells. The future challenge is to clarify the key factors associated with drug resistance and the combinations of drugs that may be clinically more effective by suppressing the EGFR pathway.

Author Contributions: Writing_original draft preparation, Y.T.; review and editing, R.T. and T.I.; supervision: T.I. All authors have read and agreed to the published version of the manuscript.

Funding: This research received no external funding.

Institutional Review Board Statement: Not applicable.

Informed Consent Statement: Not applicable.

Data Availability Statement: Not applicable.

Acknowledgments: We appreciate Xuexia Tong, Sun Rong, and Eshat Fahmida Haque for their technical support.

Conflicts of Interest: Y.T. received honoraria from Daiichi Dankyo K.K., AstraZeneca K.K., and Chugai Pharmaceutical instead of lecture fees, regardless of this work. T.I. received honoraria from Boehringer Ingelheim, Pfizer, Daiichi-Sankyo K.K., and AstraZeneca K.K., instead of lecture fees, regardless of this work. 


\section{References}

1. Lynch, T.J.; Bell, D.W.; Sordella, R.; Gurubhagavatula, S.; Okimoto, R.A.; Brannigan, B.W.; Harris, P.L.; Haserlat, S.M.; Supko, J.G.; Haluska, F.G.; et al. Activating Mutations in the Epidermal Growth Factor Receptor Underlying Responsiveness of Non-Small-Cell Lung Cancer to Gefitinib. N. Engl. J. Med. 2004, 350, 2129-2139. [CrossRef] [PubMed]

2. Maemondo, M.; Inoue, A.; Kobayashi, K.; Sugawara, S.; Oizumi, S.; Isobe, H.; Gemma, A.; Harada, M.; Yoshizawa, H.; Kinoshita, I.; et al. Gefitinib or Chemotherapy for Non-Small-Cell Lung Cancer with Mutated EGFR. N. Engl. J. Med. 2010, 362, $2380-2388$. [CrossRef] [PubMed]

3. Mitsudomi, T.; Morita, S.; Yatabe, Y.; Negoro, S.; Okamoto, I.; Tsurutani, J.; Seto, T.; Satouchi, M.; Tada, H.; Hirashima, T.; et al. Gefitinib versus cisplatin plus docetaxel in patients with non-small-cell lung cancer harbouring mutations of the epidermal growth factor receptor (WJTOG3405): An open label, randomised phase 3 trial. Lancet Oncol. 2010, 11, 121-128. [CrossRef]

4. Peters, S.; Camidge, D.R.; Shaw, A.T.; Gadgeel, S.; Ahn, J.S.; Kim, D.W.; Ou, S.H.I.; Pérol, M.; Dziadziuszko, R.; Rosell, R.; et al. Alectinib Versus Crizotinib in Untreated ALK-positive Non-Small-Cell Lung Cancer. N. Engl. J. Med. 2017, 377, 829-838. [CrossRef]

5. Shaw, A.T.; Riely, G.J.; Bang, Y.J.; Kim, D.W.; Camidge, D.R.; Solomon, B.J.; Varella-Garcia, M.; Iafrate, A.J.; Shapiro, G.I.; Usari, T.; et al. Crizotinib in ROS1-Rearranged Advanced Non-Small-Cell Lung Cancer (NSCLC): Updated Results, Including Overall Survival, From PROFILE 1001. Ann. Oncol. 2019, 30, 1121-1126. [CrossRef]

6. Planchard, D.; Smit, E.F.; Groen, H.J.; Mazieres, J.; Besse, B.; Helland, Å.; Giannone, V.; D’Amelio, A.M., Jr.; Zhang, P.; Mookerjee, B.; et al. Dabrafenib Plus Trametinib in Patients with Previously Untreated BRAF (V600E)-Mutant Metastatic Non-Small-Cell Lung Cancer: An Open-Label, Phase 2 Trial. Lancet Oncol. 2017, 18, 1307-1316. [CrossRef]

7. Doebele, R.C.; Drilon, A.; Paz-Ares, L.; Siena, S.; Shaw, A.T.; Farago, A.F.; Blakely, C.M.; Seto, T.; Cho, B.C.; Tosi, D.; et al. Entrectinib in patients with advanced or metastatic NTRK fusion-positive solid tumours: Integrated analysis of three phase 1-2 trials. Lancet Oncol. 2020, 21, 271-282. [CrossRef]

8. Paik, P.K.; Felip, E.; Veillon, R.; Sakai, H.; Cortot, A.B.; Garassino, M.C.; Mazieres, J.; Viteri, S.; Senellart, H.; Van Meerbeeck, J.; et al. Tepotinib in Non-Small-Cell Lung Cancer with MET Exon 14 Skipping Mutations. N. Engl. J. Med. 2020, 383, 931-943. [CrossRef]

9. Mok, T.S.; Wu, Y.-L.; Ahn, M.-J.; Garassino, M.C.; Kim, H.R.; Ramalingam, S.S.; Shepherd, F.A.; He, Y.; Akamatsu, H.; Theelen, W.S.; et al. Osimertinib or Platinum-Pemetrexed in EGFR T790M-Positive Lung Cancer. N. Engl. J. Med. 2017, 376, 629-640. [CrossRef]

10. Kohno, T.; Nakaoku, T.; Tsuta, K.; Tsuchihara, K.; Matsumoto, S.; Yoh, K.; Goto, K. Beyond ALK-RET, ROS1 and Other On-cogene Fusions in Lung Cancer. Transl. Lung Cancer Res. 2015, 4, 156-164.

11. Kobayashi, Y.; Mitsudomi, T. Not All Epidermal Growth Factor Receptor Mutations in Lung Cancer Are Created Equal: Perspectives for Individualized Treatment Strategy. Cancer Sci. 2016, 107, 1179-1186. [CrossRef]

12. Yasuda, H.; Kobayashi, S.; Costa, D. EGFR exon 20 insertion mutations in non-small-cell lung cancer: Preclinical data and clinical implications. Lancet Oncol. 2012, 13, e23-e31. [CrossRef]

13. Rosell, R.; Carcereny, E.; Gervais, R.; Vergnenegre, A.; Massuti, B.; Felip, E.; Palmero, R.; Garcia-Gomez, R.; Pallares, C.; Sanchez, J.M.; et al. Erlotinib versus standard chemotherapy as first-line treatment for European patients with advanced EGFR mutation-positive non-small-cell lung cancer (EURTAC): A multicentre, open-label, randomised phase 3 trial. Lancet Oncol. 2012, 13, 239-246. [CrossRef]

14. Zhou, C.; Wu, Y.-L.; Chen, G.; Feng, J.; Liu, X.-Q.; Wang, C.; Zhang, S.; Wang, J.; Zhou, S.; Ren, S.; et al. Erlotinib versus chemotherapy as first-line treatment for patients with advanced EGFR mutation-positive non-small-cell lung cancer (OPTIMAL, CTONG-0802): A multicentre, open-label, randomised, phase 3 study. Lancet Oncol. 2011, 12, 735-742. [CrossRef]

15. Park, K.; Tan, E.-H.; O’Byrne, K.; Zhang, L.; Boyer, M.; Mok, T.; Hirsh, V.; Yang, J.C.-H.; Lee, K.H.; Lu, S.; et al. Afatinib versus gefitinib as first-line treatment of patients with EGFR mutation-positive non-small-cell lung cancer (LUX-Lung 7): A phase 2B, open-label, randomised controlled trial. Lancet Oncol. 2016, 17, 577-589. [CrossRef]

16. Wu, Y.-L.; Cheng, Y.; Zhou, X.; Lee, K.H.; Nakagawa, K.; Niho, S.; Tsuji, F.; Linke, R.; Rosell, R.; Corral, J.; et al. Dacomitinib versus gefitinib as first-line treatment for patients with EGFR-mutation-positive non-small-cell lung cancer (ARCHER 1050): A randomised, open-label, phase 3 trial. Lancet Oncol. 2017, 18, 1454-1466. [CrossRef]

17. Ramalingam, S.S.; Vansteenkiste, J.; Planchard, D.; Cho, B.C.; Gray, J.E.; Ohe, Y.; Zhou, C.; Reungwetwattana, T.; Cheng, Y.; Chewaskulyong, B.; et al. Overall Survival with Osimertinib in Untreated, EGFR-Mutated Advanced NSCLC. N. Engl. J. Med. 2020, 382, 41-50. [CrossRef] [PubMed]

18. Planchard, D.; Feng, P.-H.; Karaseva, N.; Kim, S.-W.; Kim, T.; Lee, C.; Poltoratskiy, A.; Yanagitani, N.; Marshall, R.; Huang, X.; et al. Osimertinib plus platinum-pemetrexed in newly diagnosed epidermal growth factor receptor mutation-positive advanced/metastatic non-small-cell lung cancer: Safety run-in results from the FLAURA2 study. ESMO Open 2021, 6, 100271. [CrossRef]

19. Kenmotsu, H.; Wakuda, K.; Mori, K.; Kato, T.; Sugawara, S.; Kirita, K.; Okamoto, I.; Azuma, K.; Nishino, K.; Teraoka, S.; et al. Primary Results of a Randomized Phase II Study of Osimertinib Plus Bevacizumab Versus Osimertinib Monotherapy for Un-treated Patients with Non-Squamous Non-Small Cell Lung Cancer Harboring EGFR Mutations: WJOG9717L Study. Ann. Oncol. 2021, 32, LBA44. [CrossRef] 
20. Hosomi, Y.; Morita, S.; Sugawara, S.; Kato, T.; Fukuhara, T.; Gemma, A.; Takahashi, K.; Fujita, Y.; Harada, T.; Minato, K.; et al. Gefitinib Alone Versus Gefitinib Plus Chemotherapy for Non-Small-Cell Lung Cancer with Mutated Epidermal Growth Factor Receptor: NEJ009 Study. J. Clin. Oncol. 2020, 38, 115-123. [CrossRef]

21. Noronha, V.; Patil, V.M.; Joshi, A.; Menon, N.; Chougule, A.; Mahajan, A.; Janu, A.; Purandare, N.; Kumar, R.; More, S.; et al. Gefitinib Versus Gefitinib Plus Pemetrexed and Carboplatin Chemotherapy in EGFR-Mutated Lung Cancer. J. Clin. Oncol. 2020, 38, 124-136. [CrossRef] [PubMed]

22. Saito, H.; Fukuhara, T.; Furuya, N.; Watanabe, K.; Sugawara, S.; Iwasawa, S.; Tsunezuka, Y.; Yamaguchi, O.; Okada, M.; Yoshimori, K.; et al. Erlotinib Plus Bevacizumab Versus Erlotinib Alone in Patients With EGFR-Positive Advanced Non-Squamous Non-Small-Cell Lung Cancer (NEJ026): Interim Analysis of an Open-Label, Randomised, Multicentre, phase 3 Trial. Lancet Oncol. 2019, 20, 625-635. [CrossRef]

23. Kawashima, Y.; Fukuhara, T.; Saito, H.; Furuya, N.; Watanabe, K.; Sugawara, S.; Iwasawa, S.; Tsunezuka, Y.; Yamaguchi, O.; Okada, M.; et al. Bevacizumab plus erlotinib versus erlotinib alone in Japanese patients with advanced, metastatic, EGFR-mutant non-small-cell lung cancer (NEJ026): Overall survival analysis of an open-label, randomised, multicentre, phase 3 trial. Lancet Respir. Med. 2021. Online ahead of print. [CrossRef]

24. Nakagawa, K.; Garon, E.B.; Seto, T.; Nishio, M.; Aix, S.P.; Paz-Ares, L.; Chiu, C.-H.; Park, K.; Novello, S.; Nadal, E.; et al. Ramucirumab plus erlotinib in patients with untreated, EGFR-mutated, advanced non-small-cell lung cancer (RELAY): A randomised, double-blind, placebo-controlled, phase 3 trial. Lancet Oncol. 2019, 20, 1655-1669. [CrossRef]

25. Meng, F.; Wang, F.; Wang, L.; Wong, S.C.C.; Cho, W.C.S.; Chan, L.W.C. MiR-30a-5p Overexpression May Overcome EGFR-Inhibitor Resistance through Regulating PI3K/AKT Signaling Pathway in Non-small Cell Lung Cancer Cell Lines. Front. Genet. 2016, 7, 197. [CrossRef] [PubMed]

26. Kitamura, H.; Ohno, Y.; Toyoshima, Y.; Ohtake, J.; Homma, S.; Kawamura, H.; Takahashi, N.; Taketomi, A. Interleu-kin-6/STAT3 Signaling as a Promising Target to Improve the Efficacy of Cancer Immunotherapy. Cancer Sci. 2017, 108, 1947-1952. [CrossRef]

27. Johnson, D.E.; O'Keefe, R.A.; Grandis, J.R. Targeting the IL-6/JAK/STAT3 signalling axis in cancer. Nat. Rev. Clin. Oncol. 2018, 15, 234-248. [CrossRef]

28. Ota, K.; Azuma, K.; Kawahara, A.; Hattori, S.; Iwama, E.; Tanizaki, J.; Harada, T.; Matsumoto, K.; Takayama, K.; Takamori, S.; et al. Induction of PD-L1 Expression by the EML4-ALK Oncoprotein and Downstream Signaling Pathways in Non-Small Cell Lung Cancer. Clin. Cancer Res. 2015, 21, 4014-4021. [CrossRef]

29. Yang, C.-Y.; Liao, W.-Y.; Ho, C.-C.; Chen, K.-Y.; Tsai, T.-H.; Hsu, C.-L.; Su, K.-Y.; Chang, Y.-L.; Wu, C.-T.; Liao, B.-C.; et al. Association between programmed death-ligand 1 expression, immune microenvironments, and clinical outcomes in epidermal growth factor receptor mutant lung adenocarcinoma patients treated with tyrosine kinase inhibitors. Eur. J. Cancer 2020, 124, 110-122. [CrossRef]

30. Haratani, K.; Hayashi, H.; Tanaka, T.; Kaneda, H.; Togashi, Y.; Sakai, K.; Hayashi, K.; Tomida, S.; Chiba, Y.; Yonesaka, K.; et al. Tumor immune microenvironment and nivolumab efficacy in EGFR mutation-positive non-small-cell lung cancer based on T790M status after disease progression during EGFR-TKI treatment. Ann. Oncol. 2017, 28, 1532-1539. [CrossRef]

31. Isomoto, K.; Haratani, K.; Hayashi, H.; Shimizu, S.; Tomida, S.; Niwa, T.; Yokoyama, T.; Fukuda, Y.; Chiba, Y.; Kato, R.; et al. Impact of EGFR-TKI Treatment on the Tumor Immune Microenvironment in EGFR Mutation-Positive Non-Small Cell Lung Cancer. Clin. Cancer Res. 2020, 26, 2037-2046. [CrossRef]

32. Inomata, M.; Azechi, K.; Takata, N.; Hayashi, K.; Tokui, K.; Taka, C.; Okazawa, S.; Kambara, K.; Imanishi, S.; Miwa, T.; et al. Association of Tumor PD-L1 Expression with the T790M Mutation and Progression-Free Survival in Patients with EGFR-Mutant Non-Small Cell Lung Cancer Receiving EGFR-TKI Therapy. Diagnostics 2020, 10, 1006. [CrossRef]

33. Kobayashi, K.; Seike, M.; Zou, F.; Noro, R.; Chiba, M.; Ishikawa, A.; Kunugi, S.; Kubota, K.; Gemma, A. Prognostic Significance of NSCLC and Response to EGFR-TKIs of EGFR-Mutated NSCLC Based on PD-L1 Expression. Anticancer. Res. 2018, 38, 753-762. [PubMed]

34. Gandhi, L.; Rodríguez-Abreu, D.; Gadgeel, S.; Esteban, E.; Felip, E.; De Angelis, F.; Domine, M.; Clingan, P.; Hochmair, M.J.; Powell, S.F.; et al. Pembrolizumab plus Chemotherapy in Metastatic Non-Small-Cell Lung Cancer. N. Engl. J. Med. 2018, 378, 2078-2092. [CrossRef] [PubMed]

35. Reck, M.; Mok, T.S.; Nishio, M.; Jotte, R.M.; Cappuzzo, F.; Orlandi, F.; Stroyakovskiy, D.; Nogami, N.; Rodríguez-Abreu, D.; Moro-Sibilot, D.; et al. Atezolizumab Plus Bevacizumab and Chemotherapy in Non-Small-Cell Lung Cancer (IMpower150): Key Subgroup Analyses of Patients with EGFR Mutations or Baseline Liver Me-tastases in a Randomised, Open-Label Phase 3 Trial. Lancet Respir. Med. 2019, 7, 387-401. [CrossRef]

36. Hayashi, H.; Sugawara, S.; Fukuda, Y.; Sato, Y.; Miura, S.; Ota, K.; Ozawa, Y.; Hara, S.; Tanizaki, J.; Azuma, K.; et al. A randomized phase II study comparing nivolumab (NIVO) with carboplatin-pemetrexed (CbPEM) for patients (pts) with EGFR mutation-positive non-small cell lung cancer (NSCLC) who acquire resistance to tyrosine kinase inhibitors (TKIs) not due to a secondary T790M mutation (WJOG8515L). J. Clin. Oncol. 2021, 39, 9037.

37. Nguyen, K.-S.H.; Kobayashi, S.; Costa, D.B. Acquired Resistance to Epidermal Growth Factor Receptor Tyrosine Kinase Inhibitors in Non-Small-Cell Lung Cancers Dependent on the Epidermal Growth Factor Receptor Pathway. Clin. Lung Cancer 2009, 10, 281-289. [CrossRef] 
38. Sequist, L.V.; Waltman, B.A.; Dias-Santagata, D.; Digumarthy, S.; Turke, A.B.; Fidias, P.; Bergethon, K.; Shaw, A.T.; Gettinger, S.; Cosper, A.K.; et al. Genotypic and Histological Evolution of Lung Cancers Acquiring Resistance to EGFR Inhibitors. Sci. Transl. Med. 2011, 3, 75ra26. [CrossRef]

39. Wheeler, D.L.; Dunn, E.F.; Harari, P.M. Understanding resistance to EGFR inhibitors-Impact on future treatment strategies. Nat. Rev. Clin. Oncol. 2010, 7, 493-507. [CrossRef]

40. Kobayashi, S.; Boggon, T.J.; Dayaram, T.; Jänne, P.A.; Kocher, O.; Meyerson, M.; Johnson, B.E.; Eck, M.J.; Tenen, D.G.; Halmos, B. EGFR mutation and resistance of non-small-cell lung cancer to gefitinib. N. Engl. J. Med. 2005, 352, 786-792. [CrossRef]

41. Aparicio, S.; Caldas, C. The Implications of Clonal Genome Evolution for Cancer Medicine. N. Engl. J. Med. 2013, 368, 842-851. [CrossRef] [PubMed]

42. Watanabe, M.; Kawaguchi, T.; Isa, S.-I.; Ando, M.; Tamiya, A.; Kubo, A.; Saka, H.; Takeo, S.; Adachi, H.; Tagawa, T.; et al. UltraSensitive Detection of the Pretreatment EGFR T790M Mutation in Non-Small Cell Lung Cancer Patients with an EGFR-Activating Mutation Using Droplet Digital PCR. Clin. Cancer Res. 2015, 21, 3552-3560. [CrossRef]

43. Arcila, M.E.; Oxnard, G.R.; Nafa, K.; Riely, G.J.; Solomon, S.B.; Zakowski, M.F.; Kris, M.G.; Pao, W.; Miller, V.A.; Ladanyi, M. Rebiopsy of Lung Cancer Patientswith Acquired Resistance to EGFR Inhibitors and Enhanced Detection of the T790M Mutation Using a Locked Nucleic Acid-Based Assay. Clin. Cancer Res. 2011, 17, 1169-1180. [CrossRef] [PubMed]

44. Suda, K.; Mizuuchi, H.; Maehara, Y.; Mitsudomi, T. Acquired resistance mechanisms to tyrosine kinase inhibitors in lung cancer with activating epidermal growth factor receptor mutation-diversity, ductility, and destiny. Cancer Metastasis Rev. 2012, 31, 807-814. [CrossRef]

45. Jacobsen, K.; Bertran-Alamillo, J.; Molina, M.A.; Teixidó, C.; Karachaliou, N.; Pedersen, M.H.; Castellvi, J.; Garzón, M.; Servat, C.C.; Codony-Servat, J.; et al. Convergent Akt activation drives acquired EGFR inhibitor resistance in lung cancer. Nat. Commun. 2017, 8, 1-14. [CrossRef]

46. Oxnard, G.R.; Hu, Y.; Mileham, K.F.; Husain, H.; Costa, D.B.; Tracy, P.; Feeney, N.; Sholl, L.M.; Dahlberg, S.E.; Redig, A.J.; et al. Assessment of Resistance Mechanisms and Clinical Implications in Patients with EGFR T790M-Positive Lung Cancer and Acquired Resistance to Osimertinib. JAMA Oncol. 2018, 4, 1527-1534. [CrossRef]

47. Leonetti, A.; Sharma, S.; Minari, R.; Perego, P.; Giovannetti, E.; Tiseo, M. Resistance mechanisms to osimertinib in EGFR-mutated non-small cell lung cancer. Br. J. Cancer 2019, 121, 725-737. [CrossRef] [PubMed]

48. Jia, Y.; Yun, C.-H.; Park, E.; Ercan, D.; Manuia, M.; Juarez, J.; Xu, C.; Rhee, K.; Chen, T.; Zhang, H.; et al. Overcoming EGFR(T790M) and EGFR(C797S) resistance with mutant-selective allosteric inhibitors. Nature 2016, 534, 129-132. [CrossRef]

49. Bauml, J.; Cho, B.C.; Park, K.; Lee, K.H.; Cho, E.K.; Kim, D.-W.; Kim, S.-W.; Haura, E.B.; Sabari, J.K.; Sanborn, R.E.; et al. Amivantamab in combination with lazertinib for the treatment of osimertinib-relapsed, chemotherapy-naïve EGFR mutant (EGFRm) non-small cell lung cancer (NSCLC) and potential biomarkers for response. J. Clin. Oncol. 2021, 39, 9006. [CrossRef]

50. Janne, P.A.; Baik, C.S.; Su, W.C.; Johnson, M.L.; Hayashi, H.; Nishio, M.; Kim, D.W.; Koczywas, M.; Gold, K.A.; Steuer, C.E.; et al. Efficacy and Safety of Patritumab Deruxtecan (HER3-DXd) in EGFR Inhibitor-Resistant, EGFR-Mutated (EGFRm) Non-Small Cell Lung Cancer (NSCLC). J. Clin. Oncol. 2021, 39, 9007. [CrossRef]

51. Siravegna, G.; Marsoni, S.; Siena, S.; Bardelli, A. Integrating liquid biopsies into the management of cancer. Nat. Rev. Clin. Oncol. 2017, 14, 531-548. [CrossRef] [PubMed]

52. Tsubata, Y.; Watanabe, K.; Saito, R.; Nakamura, A.; Yoshioka, H.; Morita, M.; Honda, R.; Kanaji, N.; Ohizumi, S.; Jingu, D.; et al. Osimertinib in poor performance status patients with T790M-positive advanced non-small-cell lung cancer after progression of first- and second-generation EGFR-TKI treatments (NEJ032B). Int. J. Clin. Oncol. 2021. Online ahead of print. [CrossRef]

53. Fukuhara, T.; Saito, H.; Furuya, N.; Watanabe, K.; Sugawara, S.; Iwasawa, S.; Tsunezuka, Y.; Yamaguchi, O.; Okada, M.; Yoshimori, K.; et al. Evaluation of plasma EGFR mutation as an early predictor of response of erlotinib plus bevacizumab treatment in the NEJ026 study. EBioMedicine 2020, 57, 102861. [CrossRef] [PubMed]

54. Oxnard, G.R.; Paweletz, C.P.; Kuang, Y.; Mach, S.L.; O'Connell, A.; Messineo, M.M.; Luke, J.J.; Butaney, M.; Kirschmeier, P.; Jackman, D.M.; et al. Noninvasive Detection of Response and Resistance in EGFR-Mutant Lung Cancer Using Quanti-tative Next-Generation Genotyping of Cell-Free Plasma DNA. Clin. Cancer Res. 2014, 20, 1698-1705. [CrossRef]

55. Ebert, E.B.F.; McCulloch, T.; Hansen, K.H.; Linnet, H.; Sorensen, B.; Meldgaard, P. Clearing of circulating tumour DNA predicts clinical response to osimertinib in EGFR mutated lung cancer patients. Lung Cancer 2020, 143, 67-72. [CrossRef] [PubMed]

56. Hata, A.N.; Niederst, M.J.; Archibald, H.L.; Gomez-Caraballo, M.; Siddiqui, F.M.; Mulvey, H.E.; Maruvka, Y.E.; Ji, F.; Bhang, H.-E.C.; Radhakrishna, V.K.; et al. Tumor cells can follow distinct evolutionary paths to become resistant to epidermal growth factor receptor inhibition. Nat. Med. 2016, 22, 262-269. [CrossRef] [PubMed]

57. Tanino, R.; Tsubata, Y.; Harashima, N.; Harada, M.; Isobe, T. Novel drug-resistance mechanisms of pemetrexed-treated non-small cell lung cancer. Oncotarget 2018, 9, 16807-16821. [CrossRef]

58. Chen, K.-C.; Yang, T.-Y.; Wu, C.-C.; Cheng, C.-C.; Hsu, S.-L.; Hung, H.-W.; Chen, J.-W.; Chang, G.-C. Pemetrexed Induces S-Phase Arrest and Apoptosis via a Deregulated Activation of Akt Signaling Pathway. PLoS ONE 2014, 9, e97888. [CrossRef]

59. Tong, X.; Tanino, R.; Sun, R.; Tsubata, Y.; Okimoto, T.; Takechi, M.; Isobe, T. Protein tyrosine kinase 2: A novel therapeutic target to overcome acquired EGFR-TKI resistance in non-small cell lung cancer. Respir. Res. 2019, 20, 1-14. [CrossRef]

60. Suda, K.; Bunn, P.A., Jr.; Rivard, C.J.; Mitsudomi, T.; Hirsch, F.R. Primary Double-Strike Therapy for Cancers to Overcome EGFR Kinase Inhibitor Resistance: Proposal from the Bench. J. Thorac. Oncol. 2017, 12, 27-35. [CrossRef] 
61. Itatani, Y.; Kawada, K.; Yamamoto, T.; Sakai, Y. Resistance to Anti-Angiogenic Therapy in Cancer-Alterations to Anti-VEGF Pathway. Int. J. Mol. Sci. 2018, 19, 1232. [CrossRef] [PubMed]

62. Haibe, Y.; Kreidieh, M.; Haji, H.E.; Khalifeh, I.; Mukherji, D.; Temraz, S.; Shamseddine, A. Resistance Mechanisms to An-tiangiogenic Therapies in Cancer. Front. Oncol. 2020, 10, 221. [CrossRef] [PubMed]

63. Akamatsu, H.; Toi, Y.; Hayashi, H.; Fujimoto, D.; Tachihara, M.; Furuya, N.; Otani, S.; Shimizu, J.; Katakami, N.; Azuma, K.; et al. Efficacy of Osimertinib Plus Bevaci-zumab vs Osimertinib in Patients with EGFR T790M-Mutated Non-Small Cell Lung Cancer Previously Treated with Epidermal Growth Factor Receptor-Tyrosine Kinase Inhibitor: West Japan Oncology Group 8715L Phase 2 Randomized Clinical Trial. JAMA Oncol. 2021, 7, 386-394. [PubMed] 